\title{
Derechos ambientales y obligaciones en el sistema interamericano de derechos humanos
}

Este comentario, junto a los documentos que analiza, está disponible en www.anuariocdh.uchile.cl

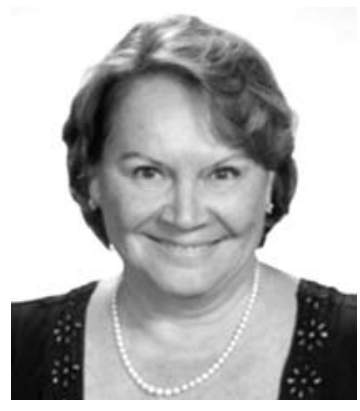

\section{Dinah Shelton}

B.A., J.D., Universidad de California, Berkeley. Profesora Manatt/Ahn de Derecho Internacional de The George Washington University Law School. Comisionada de la Comisión Interamericana de Derechos Humanos.

dshelton@law.qwu.edu

\section{RESUMEN}

En el presente artículo se analizan las normas y jurisprudencia sobre derechos ambientales y las obligaciones de los Estados conforme a su desarrollo en el Sistema Interamericano de Derechos Humanos. Se observa que la Comisión y la Corte Interamericanas han establecido una amplia serie de obligaciones estatales con el fin de mantener el medio ambiente a un nivel de calidad que permita el disfrute de los derechos garantizados. Asimismo, los organismos de la OEA se han hecho eco de la insistencia mundial respecto de los derechos procesales de información, participación pública y acceso a la justicia. Mientras muchos casos interamericanos han surgido en el marco del conflicto entre gobiernos nacionales y pueblos indígenas en relación con la tierra y los recursos naturales, existen otros casos que han dejado en claro los límites más amplios de un enfoque basado en los derechos en cuanto a la protección del medio ambiente en el sistema interamericano.

\section{Introducción}

En las cuatro décadas que han transcurrido desde que las Naciones Unidas convocó la primera conferencia ambiental en Estocolmo, casi todos los organismos mundiales y regionales de derechos humanos han analizado los vínculos entre el deterioro del medio ambiente y los derechos humanos protegidos por garantías internacionales. Los procedimientos internacionales para la presentación de peticiones relacionadas con los derechos humanos permiten que aquellos cuyos derechos se han visto perjudicados por las condiciones ambientales recurran a la presión internacional cuando los gobiernos carecen de la voluntad necesaria para impedir o frenar la grave contaminación que amenaza el bienestar de los seres humanos. Mediante estos procedimientos, personas y grupos han invocado el derecho a la vida, la salud, la propiedad, la información, la privacidad y la vida hogareña, para quejarse contra la contaminación, deforestación y otros tipos de daño ambiental. En muchos casos, los peticionarios han logrado reparaciones y los gobiernos han adoptado medidas destinadas a remediar la infracción. Los procedimientos de petición también pueden contribuir a identificar los problemas y fomentar el diálogo para resolverlos, incluso mediante la entrega de asistencia técnica. 
Los vínculos entre los derechos humanos y la protección del medio ambiente eran evidentes para los Estados, organizaciones internacionales y representantes de la sociedad civil que se reunieron en Estocolmo en 1972. La relación entre ambos se expresó en la introducción a la declaración final, en la que los participantes proclaman que:

El hombre es a la vez obra y artífice del medio que lo rodea, el cual le da el sustento material y le brinda la oportunidad de desarrollarse intelectual, moral, social y espiritualmente... Los dos aspectos del medio humano, el natural y el artificial, son esenciales para el bienestar del hombre y para el goce de los derechos humanos fundamentales, incluso el derecho a la vida misma ${ }^{1}$.

El Principio 1 de la Declaración de Estocolmo estableció, además, los fundamentos para vincular los derechos humanos con la protección del medio ambiente, al señalar que:

El hombre tiene el derecho fundamental a la libertad, la igualdad y el disfrute de condiciones de vida adecuadas en un medio de calidad tal que le permita llevar una vida digna y gozar de bienestar $[\ldots]$.

La formulación del Principio 1 no llega a declarar el derecho a un medio ambiente sano pero, en cambio, se refiere implícitamente a los derechos civiles, políticos y económicos existentes, agrupados bajo el principio de "la libertad, la igualdad y el disfrute de condiciones de vida adecuadas".

A partir de la Conferencia de Estocolmo, los instrumentos y decisiones legales internacionales han reformulado y desarrollado dichos vínculos, reflejando con frecuencia una perspectiva basada en los derechos humanos, si bien con diferencias en cuanto al énfasis. El enfoque plasmado en la Declaración de Estocolmo entiende la protección del medio ambiente como una condición previa para el disfrute de una serie de derechos humanos que gozan de garantías internacionales. En consecuencia, la protección del medio ambiente constituye un instrumento esencial que se encuentra subsumido en el esfuerzo por garantizar efectivamente el disfrute de los derechos humanos.

Un enfoque diferente, también basado en los derechos y que aparece con mayor frecuencia en los acuerdos sobre el medio ambiente aprobados a partir de 1992, también tiene una perspectiva instrumentalista, pero difiere en cuanto considera que el ejercicio de determinados derechos humanos constituye un medio fundamental para lograr el objetivo de proteger el medio ambiente. Este enfoque está reflejado en la Declaración de Río sobre el Medio Ambiente y el Desarrollo, adoptada al concluir la Conferencia de Río de Janeiro sobre el Medio Ambiente y el Desarrollo de $1992^{2}$. La Declaración establece un vínculo entre los derechos humanos y la protección del medio ambiente principalmente en cuanto a los procedimientos, cuando señala en el Principio 10 que el acceso a la información, la participación pública y el acceso efectivo a los procedimientos judiciales y administrativos, incluyendo la reparación, se deben garantizar porque "el mejor modo de tratar las cuestiones ambientales es con la participación de todos los ciudadanos interesados, en el nivel que corresponda". En consecuencia, dichos derechos procesales, también establecidos en los instrumentos de derechos humanos, se adoptan en textos ambientales para tomar decisiones mejores en los temas ambientales, lo cual a su vez puede incrementar el cumplimiento de las normas ambientales ${ }^{3}$.

1 Declaración de la Conferencia de las Naciones Unidas sobre el Medio Ambiente Humano, 16 de junio de 1972, U.N. Doc. A/.CONF.48/14/Rev.1 No 3, 1973. Pmbl; reimpreso en: 11 I.L.M. 1416, 1972.

2 Declaración de Río sobre Medio Ambiente y Desarrollo, Informe de la Conferencia de Naciones Unidas sobre Medio Ambiente y Desarrollo, Principio 10, A/CONF.151/26/Rev.1 (Vol. 1), 3-14 junio de 1992, Anexo I, pp. 3-8. Reimpreso en: 31 I.L.M. 876, 1992.

3 FRANCK, Th. Fairness in International Law and Institutions. Oxford, Clarendon Press, 1995, pp. 7-9, 24. 
La Asamblea General de la Organización de Estados Americanos (OEA) adoptó un enfoque similar al que establece el Principio 10 de la Declaración de Río. En el año 2001 aprobó por primera vez una cautelosa resolución sobre derechos humanos y medio ambiente ${ }^{4}$. La resolución destacaba, en primer lugar, la importancia de analizar el vínculo que "pudiera existir" entre el medio ambiente y los derechos humanos y luego abordaba la necesidad de promover la protección del medio ambiente y el goce efectivo de todos los derechos humanos. Asimismo, solicitaba a la Secretaría General que Ilevara a cabo un estudio acerca de la "posible interrelación entre la protección ambiental y el pleno goce de los derechos humanos...". En otra resolución (AG/RES 1819), aprobada durante la misma sesión, la Asamblea General describe a los derechos humanos como un mecanismo para incrementar la protección del medio ambiente, al señalar que:

[E]l efectivo goce de todos los derechos humanos [...] podría facilitar una mejor protección del medio ambiente, mediante la creación de condiciones para modificar los patrones de conducta que conllevan la alteración del ambiente, la reducción del impacto ambiental derivado de la pobreza y patrones de desarrollo no sostenibles, la difusión más efectiva de información sobre el problema, y la participación más activa de los grupos afectados por el problema en los procesos políticos.

En términos más generales, el marco de legislación nacional e internacional sobre medio ambiente que ha surgido en el transcurso de los últimos cuarenta años ha llegado a incluir una gran variedad de enfoques y técnicas legales orientadas a la conservación de los recursos naturales y la protección de los procesos ambientales de los que depende la vida. Entre las técnicas habituales, que suelen surgir a partir de la experiencia de un solo Estado, se cuentan las siguientes: determinación de normas de calidad, de los productos o de la emisión; licenciamiento y otras formas de regular las actividades peligrosas; generación de incentivos o desincentivos económicos; sanciones para actividades especialmente dañinas para el medio ambiente por medio del derecho penal; y creación de regímenes de responsabilidad privada con el fin de desalentar y subsanar el daño ambiental. En este variado conjunto ha ido aumentando gradualmente la importancia de los enfoques basados en los derechos. A partir de 1972, más de la mitad de los Estados miembros de Naciones Unidas han agregado garantías constitucionales respecto del medio ambiente ${ }^{5}$, muchas de las cuales declaran o agregan un derecho explícito a una calidad específica del medio ambiente. Dichas formulaciones pueden acotar el derecho al medio ambiente mediante términos tales como "sano", "seguro" o "limpio".

Este artículo analiza las normas y la jurisprudencia sobre derechos ambientales y obligaciones estatales conforme han ido surgiendo en el Sistema Interamericano de Derechos Humanos. Este trabajo establece que, a pesar de la ausencia de referencia al medio ambiente en casi todos los instrumentos normativos interamericanos, la Comisión y la Corte Interamericanas han construido una amplia gama de obligaciones estatales destinadas a mantener un grado de calidad en el medio ambiente que permita disfrutar de los derechos garantizados. Asimismo, los organismos de la OEA se han sumado a la insistencia global respecto de los derechos procesales a la información, participación pública y acceso a la justicia. Si bien numerosos casos interamericanos han surgido en el contexto de controversias entre gobiernos nacionales y pueblos indígenas por motivos relacionados con la tierra y los recursos naturales, otros casos han puesto de relieve algunos de los aspectos más generales de un enfoque basado en los derechos en lo referente a la protección del medio ambiente en el sistema interamericano. En última instancia, parece evidente que los Estados

4 Derechos Humanos y Medio Ambiente. Resolución adoptada en la tercera sesión plenaria, 5 de junio de 2001, OEA/ SerieG, AG/RES.1219 (XXXI-O/01).

5 EARTHJUSTICE. Environmental Rights Report 2007: Human Rights and the Environment, Appendix (incluye disposiciones constitucionales sobre el medio ambiente de 118 países), 2007, [en línea] http://www.earthjustice.org/news/press/007/ earthjustice-presents-2007-environmental-rights-report-to-un.html 
que integran la OEA no pueden hacer caso omiso del deterioro de las condiciones ambientales si han de cumplir con sus obligaciones regionales en cuanto a los derechos humanos.

\section{Instrumentos interamericanos de derechos humanos}

La Declaración de Derechos y Deberes del Hombre, de 1948 (adoptada por la Novena Conferencia Internacional de Estados Americanos, con la que concluye la Carta de la OEA), fue aprobada como resolución no vinculante de la conferencia. En la actualidad, en general se considera que la Declaración establece "los derechos fundamentales de la persona humana" tal y como aparecen en el Artículo 3 (I) de la Carta de la OEA. La Corte Interamericana de Derechos Humanos estableció que "Para los Estados Miembros de la Organización, la Declaración es el texto que determina cuáles son los derechos humanos a que se refiere la Carta" ${ }^{6}$ y, en consecuencia, constituye una fuente de obligación legal. Si bien no hace mención del medio ambiente -hecho que no resulta Ilamativo en un texto aprobado en el año 1948- los derechos establecidos incluyen el derecho a la vida, la igualdad ante la ley, el derecho de residencia y tránsito, el acceso a la justicia y el debido proceso, y los derechos a la privacidad, propiedad, trabajo y a la salud, cada uno de los cuales está vinculado a las condiciones ambientales.

La Convención Americana sobre Derechos Humanos (que se adoptó en 1969 y entró en vigencia en 1978) fundamentalmente protege derechos civiles y políticos y define con mayor detalle algunos de los derechos establecidos en la Declaración Americana. Sin embargo, el Artículo 26 de la Convención exige que los Estados Partes desarrollen medidas en forma progresiva con el fin de "lograr progresivamente la plena efectividad de los derechos que se derivan de las normas económicas, sociales y sobre educación, ciencia y cultura contenidas en la Carta...". La ampliación de tales derechos se logró con la adopción -en 1988- del Protocolo adicional a la Convención en materia de derechos económicos, sociales y culturales. El Protocolo se destaca por la inclusión del "derecho a vivir en un medio ambiente sano" y el deber de las partes de promover "la protección, preservación y mejoramiento del medio ambiente" ${ }^{\prime 7}$.

Por último, al igual que Naciones Unidas, la OEA ha trabajado durante muchos años en la redacción de una Declaración de los Derechos de los Pueblos Indígenas. La versión preliminar de la Declaración Americana de los Derechos de los Pueblos Indígenas actualmente incluye el Artículo XVIII, que analiza la protección de un medio ambiente sano. Todavía hay bastante controversia respecto del texto y falta de consenso sobre aspectos esenciales de este artículo. El proyecto preliminar analiza una amplia gama de derechos para los pueblos indígenas que abarcan desde, por ejemplo, el derecho a contar con un medio ambiente seguro y sano, el manejo sostenible de la tierra, la participación efectiva en actividades que afecten sus tierras, la prohibición estatal de la existencia de materiales peligrosos en tierras indígenas hasta la creación de sus propias áreas de protección ${ }^{8}$.

Por lo general, en lo que se refiere a los instrumentos de derechos humanos de los cuales se han hecho parte, los Estados tienen el deber no sólo de respetar la observancia de los derechos y las libertades, sino también de garantizar su existencia y libre ejercicio frente a actores privados

6 Corte IDH. Interpretación de la Declaración Americana de los Derechos y Deberes del Hombre en el Marco del artículo 64 de la Convención Americana sobre Derechos Humanos. Opinión Consultiva OC-10/89 del 14 de julio de 1989. Serie A No. 10, párrs. 43, 45, 47.

7 OEA. Protocolo Adicional a la Convención Americana sobre Derechos Humanos en materia de Derechos Económicos, Sociales y Culturales, artículos 11, 17 de noviembre de 1988, O.A.S.T.S. No. 69, 28 I.L.M. 161, inciso 63.

8 Ver Tenth Meeting of Negotiations in the Quest For Points Of Consensus, La Paz, Bolivia-April 23-27, 2007, OAS doc. OEA/SerieK/XVI, GT/DADIN/doc.301/07, 27 de abril de 2007. 
y estatales. En consecuencia, cualquier acto u omisión de una autoridad pública que ocasione menoscabo a los derechos garantizados puede constituir una violación de los deberes del Estado ${ }^{9}$. Este punto resulta especialmente importante en lo que se refiere al medio ambiente donde la mayoría de las actividades perjudiciales son llevadas a cabo por el sector privado. En consecuencia, las demandas de derechos humanos generalmente persiguen la responsabilidad estatal basadas en la ausencia de regulación en una determinada materia o de hacer cumplir la ley más que en la contaminación ocasionada directamente por la conducta del Estado.

El surgimiento del derecho internacional del medio ambiente en el período transcurrido luego de concretarse la Declaración y la Convención Americanas es significativo porque ni la Comisión ni la Corte adhieren a una interpretación estática u "originalista" de los textos. A la inversa, ambas instituciones han afirmado que en la interpretación y aplicación de las disposiciones de los instrumentos regionales de derechos humanos se debe tomar en cuenta "la evolución en el campo del derecho internacional en materia de derechos humanos, dado que tales instrumentos fueron concebidos primero y teniendo debidamente en cuenta otras normas del derecho internacional aplicables a los Estados miembros contra los que se interpongan debidamente denuncias de violación de los derechos humanos". Tanto la Comisión como la Corte han dejado en claro que la Declaración y la Convención Americanas se deben interpretar y aplicar a la luz de los acontecimientos actuales en el campo del derecho internacional, particularmente el derecho de los derechos humanos, como queda de manifiesto en los tratados, costumbres y demás fuentes pertinentes del derecho internacional.

\section{Jurisprudencia Interamericana sobre derechos humanos y el medio ambiente}

La Comisión y la Corte Interamericanas han visto causas y la Comisión ha emitido informes de país en que se abordan las condiciones ambientales existentes en los países miembros de la OEA, debido a que dichas condiciones han afectado los derechos garantizados ya sea por la Declaración o por la Convención Americana. Con mayor frecuencia, los reclamos de los peticionarios se refieren a la violación de los derechos a la vida, la salud, la propiedad, la cultura y el acceso a la justicia, pero algunos también han citado las garantías de la libertad de religión y el respeto por la cultura. Muchos casos tienen relación con la explotación de recursos provenientes de tierras que tradicionalmente son propiedad de pueblos indígenas o son utilizadas por ellos.

El enfoque general de la Comisión en lo referente a la protección del medio ambiente ha sido reconocer que por la naturaleza y propósito del derecho de los derechos humanos impone la necesidad de un nivel básico de salud ambiental:

El respeto a la dignidad inherente de la persona es el principio en el que se basan las protecciones fundamentales del derecho a la vida y a la preservación del bienestar físico. Las condiciones de grave contaminación ambiental, que pueden causar serias enfermedades físicas, discapacidades y sufrimientos a la población local, son incompatibles con el derecho a ser respetado como ser humano $^{10}$.

9 Corte IDH. Caso Velásquez Rodríguez. Sentencia de 29 de julio de 1988. Serie C. No. 4. Párr. 155 [en adelante Caso Velásquez Rodríguez] (referido a la desaparición forzada de civiles perpetrada por el Ejército de Honduras); Caso Godínez Cruz, Sentencia del 20 de enero de 1989. Serie C. No. 5 [en adelante Caso Godínez Cruz].

10 Comisión Interamericana de Derechos Humanos. Informe sobre la Situación de los Derechos Humanos en Ecuador, OEA/SerieL/V/II.96, doc. 10 rev. 1, 24 de abril de 1997, párrafo 92 [en adelante Informe sobre Ecuador]. 


\section{i. El derecho a la vida y a la salud}

El Informe de país sobre Ecuador elaborado por la Comisión en el año 1997 señala específicamente que el disfrute del derecho a la vida, la seguridad y la integridad físicas dependen de condiciones ambientales y que la "contaminación ambiental y la degradación del medio ambiente constituyen una amenaza persistente" para estos derechos" ${ }^{\prime 11}$.

Las obligaciones positivas de acción para el Estado se derivan del artículo 4 de la Convención que garantiza el derecho de la persona a que su vida sea respetada y protegida por la ley. De esta manera, la Comisión agregó:

Los Estados partes deben tomar ciertas medidas positivas para salvaguardar la vida y la integridad física. La contaminación ambiental grave puede presentar una amenaza a la vida y la salud del ser humano, y en su debido caso puede dar lugar a la obligación del Estado de tomar medidas razonables para evitar dicho riesgo, o las medidas necesarias para responder cuando las personas han sido lesionadas ${ }^{12}$.

Ya en 1983, en su Séptimo Informe sobre los Derechos Humanos en Cuba ${ }^{13}$, la Comisión recomendó que el Estado tomara medidas específicas y que adoptara disposiciones ambientales con el fin de cumplir con su obligación de garantizar el derecho a la salud. La Comisión consideró que un medio ambiente que propicia la salud de la población es "esencial" señalando, además, que factores tales como el abastecimiento de agua, la eliminación de excretas (salubridad) o desechos industriales y el sistema de recolección de basura tienen un impacto significativo en este sentido (párrafo 41). La Comisión se refirió a las condiciones negativas existentes en Cuba, incluidas la escasez de agua y la contaminación industrial de los ríos, bahías y aguas costeras, a un nivel tal que había dado origen a zonas muertas. La Comisión determinó que "el alcantarillado se encuentra en un estado tan deplorable que frecuentemente afecta al país de manera negativa" (párrafo 51). La falta de recolección de la basura también fue considerada un serio problema (párrafo 51). La Comisión llegó a la conclusión que las prácticas en el ámbito de la higiene ambiental e industrial requerían mucho más atención de parte del gobierno y que se necesitan mejorías radicales para combatir la creciente contaminación del suelo, el aire y el agua (párrafos 60 y 61).

Por lo tanto, el gobierno no sólo es responsable de la acción estatal en cuanto a la violación de los derechos humanos, sino también si no toma las medidas necesarias para impedir la degradación del medio ambiente por otros actores. En el caso de los Yanomami vs. Brasil ${ }^{14}$ la petición presentada aducía que el gobierno violaba las disposiciones de la Declaración Americana al construir una carretera que atraviesa terreno Yanomami y autorizar la explotación por privados de los recursos de su territorio. Dichas acciones han dado origen al ingreso de personas no indígenas que han traído enfermedades contagiosas que no fueron tratadas debido a la falta de atención médica. La Comisión determinó que el gobierno había violado el derecho a la vida, la libertad y la seguridad personal del pueblo Yanomami según las garantías establecidas en el Artículo I de la Declaración, el derecho de residencia y tránsito (Artículo VIII) como también el derecho a la conservación de la salud y el bienestar (Artículo XI). Las violaciones se debían específicamente al hecho de que

11 ĺdem, inciso 88.

12 ldem.

13 Comisión Interamericana de Derechos Humanos. La Situación de los Derechos Humanos en Cuba, Séptimo Informe, OEA/SerieL/V/II.61,Doc. 29 rev. 1, 4 octubre de 1983, Capítulo XIII.

14 Comisión Interamericana de Derechos Humanos. Caso Yanomami, Res. No. 12/85, Caso 7615 (Brasil), en Informe Anual de 1984-1985, OEA/SerieL/V/II.66, doc. 10, rev. 1 (1985), 24. [en adelante Caso Yanomami]. 
el gobierno no adoptó medidas "sin previa y adecuada protección para la seguridad y salubridad de los indios Yanomami"15.

En el caso Yanomami no se entró en detalles acerca de la conducta que debe tener un gobierno ni el estándar de cuidado que exigiría la Comisión. Otros casos e informes de países han contribuido a aclarar estas cuestiones, al especificar que los gobiernos deben promulgar leyes y reglamentos pertinentes y luego hacerlos cumplir. La Comisión y la Corte han manifestado que el gobierno debe regular las actividades industriales y cualquier otra que pudiera producir condiciones ambientales de un grado tan negativo como para generar riesgos para la salud o la vida misma. En el informe de país sobre los derechos humanos en Ecuador, la Comisión respondió las acusaciones que afirmaban que las actividades de explotación petrolera producían contaminación del agua, del aire y del suelo, con lo que estaban ocasionando enfermedades e incrementando significativamente el riesgo de enfermedades graves ${ }^{16}$. La Comisión constató que el medio ambiente efectivamente estaba contaminado por lo que los habitantes estaban expuestos a subproductos tóxicos y a la contaminación del agua en el plano local (con el consiguiente peligro para los alimentos). Si bien estas actividades fueron llevadas a cabo por empresas petroleras nacionales y extranjeras, los habitantes manifestaron que el responsable era el gobierno por no haber regulado y supervisado las actividades tanto de las empresas petroleras de propiedad del Estado como las de sus concesionarios. A su vez, en las empresas habían pocas o ninguna medidas para proteger a la población afectada y se negaban, además, a aplicar controles ambientales y a utilizar las tecnologías existentes utilizadas en otros países.

El gobierno de Ecuador manifestó que había tomado las medidas que exigían el derecho regional de los derechos humanos. En junio de 1994, el Presidente había dictado un decreto supremo en que se establecía que las empresas debían preparar un Estudio de Impacto Ambiental y un Programa de Mitigación Ambiental, junto con obtener la autorización necesaria antes de poder dar inicio a actividades que pudieran ocasionar el deterioro o contaminación del medio ambiente. Asimismo, el Plan de Desarrollo de Ecuador exigía a las empresas extranjeras la aplicación de requisitos y estándares más estrictos que rigen en sus países de origen en la realización de sus operaciones en Ecuador, sin perjuicio del necesario cumplimiento de la ley ecuatoriana (que también establecía medidas en contra de la contaminación).

Indudablemente, estas medidas eran positivas y podrían haber tolerado un análisis si efectivamente se hubieran aplicado adecuadamente, pero eso no sucedió. El señalamiento de la Comisión fue claro: "Cuando el derecho a la vida, a la salud y a vivir en un ambiente sano ya esté protegido por la ley, la Convención exige la efectiva aplicación y cumplimiento de la ley"17. En el caso de Ecuador, la Comisión convino en que, a pesar de la existencia de un cuerpo emergente de reglamentos ambientales, se habían puesto en práctica pocas medidas de aplicación o ejecución de dicha normativa. La Comisión ha señalado que se suponía que el proceso de establecimiento de normas y su implementación produciría determinados resultados. En consecuencia, se esperaba que Ecuador adoptara "Ias medidas necesarias para asegurar que las acciones de sus agentes, a través de la compañía petrolera estatal, cumplan las obligaciones jurídicas tanto nacionales como internacionales"18. Asimismo, se alentaba al Estado "[...] a tomar medidas para evitar daños a las personas afectadas debido al comportamiento de los concesionarios y actores privados". Esto significaba "cerciorarse de que existen medidas de protección para que no ocurran incidentes de

\footnotetext{
15 Caso Yanomami, Párr. 10 (b).

16 Informe sobre Ecuador, p. v.

17 Informe sobre Ecuador.

18 Ídem.
} 
contaminación ambiental que amenacen la vida de los habitantes de los sectores en desarrollo"19. Por último, la Comisión señalaba que "Cuando se haya infringido el derecho a la vida[...] a causa de la contaminación ambiental, el Gobierno está obligado a responder con medidas apropiadas de investigación y desagravio" 20 .

\section{ii. Derechos humanos, medio ambiente y desarrollo}

Anticipándose a las objeciones del Estado en el sentido que el desarrollo económico es un tema prioritario, la Comisión ha reconocido la existencia del "derecho al desarrollo" y ha convenido que dicho derecho implica que cada Estado es libre de explotar sus recursos naturales, incluso a través del otorgamiento de concesiones y de la aceptación de inversiones internacionales. La Comisión precisó que las normas del sistema interamericano de derechos humanos "exigen que el desarrollo tenga lugar en condiciones tales que se respeten y se garanticen los derechos humanos de los individuos afectados". Por lo tanto, los Estados no quedan exentos de las obligaciones relativas a los derechos humanos y medio ambientales en sus proyectos de desarrollo: "la ausencia de regulación, la regulación inapropiada o la falta de supervisión en la aplicación de las normas vigentes, puede crear serios problemas al medio ambiente que se traduzcan en violaciones de derechos humanos protegidos por la Convención Americana"21.

La Comisión ha manifestado su convicción de que el desarrollo debe ser sostenible y que esto requiere la protección del medio ambiente y cita al respecto la Declaración de Principios de la Cumbre de las Américas, la cual señala que: "El progreso social y la prosperidad económica solo se pueden mantener si nuestros pueblos viven en un entorno saludable y nuestros ecosistemas y recursos naturales se utilizan cuidadosamente y de manera responsable"22. La Comisión ha recomendado otras medidas positivas para paliar el daño ambiental ligado a las condiciones económicas. En un Informe de país sobre Paraguay, emitido en el año $2001^{23}$, la Comisión Interamericana propuso que el gobierno adoptara estrategias para proteger los recursos ambientales y el capital social de las comunidades pobres, señalando que se trata de recursos que la gente puede utilizar para salir de la pobreza.

\section{iii. La tierra de los pueblos indígenas y los derechos sobre los recursos}

Cuando se trate de tierra de los pueblos indígenas y sus recursos, los proyectos de desarrollo deben respetar sus derechos de propiedad colectiva. En el caso de los Mayas de Toledo, la Comisión también reconoció la importancia del desarrollo económico para la prosperidad de los pueblos de este hemisferio, pero ratificó que "las actividades de desarrollo deben ir acompañadas de medidas adecuadas y efectivas para garantizar que las mismas no se lleven a cabo a expensas de los derechos fundamentales de las personas que pueden ser particular y negativamente afectadas, incluidas las comunidades indígenas y el medio ambiente del que dependen su bienestar físico, cultural y espiritual" 24 .

19 Ídem.

20 Ídem (capítulo VIII, análisis, párrafo final).

21 Ídem, inciso 89.

22 Ídem, inciso 94.

23 Tercer informe sobre la situación de los derechos humanos en Paraguay, OEA/SerieL/V/II.110, Doc. 52, 9 de marzo de 2001 [en adelante Tercer Informe sobre Paraguay].

24 Comunidades indígenas Mayas del Distrito de Toledo vs. Belice, Informe № 40/04, Caso 12.053 (Fondo), 12 de octubre de 2004 [en adelante Caso de los Mayas de Toledo], párrafo 150. 
En un Informe de país sobre Brasil, ${ }^{25}$ la Comisión informó sobre los obstáculos que debilitan la aplicación de los preceptos constitucionales y legales de Brasil respecto de las tierras indígenas. La creación de nuevas municipalidades que abarcan parte de las tierras de propiedad de los indígenas fue considerado un instrumento para dividir a los pueblos indígenas locales al generar un medio para atraer o sobornar a algunos dirigentes locales para que participaran en el gobierno municipal e ignoraran la estructura interna de gobierno de los indígenas, provocando así su extinción. Al mismo tiempo, la estructura municipal y las relaciones de poder que le son propias tienden a favorecer el asentamiento de personas no indígenas en esas zonas -junto con los servicios públicos y las autoridades que compiten con las que ya han proporcionado o han sido aceptadas por las autoridades indígenas. El segundo problema es la ocupación ilegal de la mayoría de las zonas indígenas, con el respaldo de las autoridades civiles locales. En tercer lugar, los nuevos caminos de acceso a estas zonas han traído enfermedades a la región y han facilitado el ingreso a ellas de usurpadores. Incluso, en algunas áreas, se han producido desalojos forzados.

La evaluación de las denuncias y la información obtenida durante una visita en terreno llevaron a la Comisión a concluir que la integridad física y cultural de los pueblos indígenas de Brasil, así como la integridad de sus tierras, están bajo una amenaza constante y están sometidas al ataque de personas y grupos privados que alteran sus vidas y usurpan sus bienes. La recomendación de la Comisión fue que el Estado agilizara la adopción del Plan Nacional de Derechos Humanos de Brasil, con la plena participación y bajo el control de los pueblos indígenas correspondientes. También se solicitó al Estado que proporcionara recursos a su agencia pertinente para realizar la demarcación de las tierras, así como la entrega de servicios de asesoramiento y consejo legal para dichos pueblos.

En el capítulo IX del Informe sobre Paraguay acerca de los derechos de los pueblos indígenas, la Comisión hace referencia a la deforestación y deterioro ecológico, en contravención de las disposiciones del artículo 64 de la Constitución paraguaya. Según las denuncias recibidas, "[e]l medio ambiente está siendo destruido por empresas ganaderas, agrícolas y forestales, que reducen sus capacidades y estrategias tradicionales tanto en cuanto a alimentación como a actividad económica"26. La Comisión también tomó nota de la contaminación del agua y la construcción de proyectos hidroeléctricos que han inundado las tierras tradicionales y destruido una biodiversidad de valor incalculable. La Comisión recomendó que el Estado adoptara las medidas necesarias para proteger al hábitat de las comunidades indígenas del deterioro del medio ambiente, haciendo especial hincapié en la protección de los bosques y los recursos de aguas que son "básicos para su salud, supervivencia como comunidades" 27.

Los pueblos indígenas podrán invocar el derecho de propiedad para proteger sus tierras tradicionales y sus recursos de la explotación y el deterioro del medio ambiente. La Comisión ha instado a los Estados a adoptar medidas encaminadas a restaurar, proteger y preservar los derechos de los pueblos indígenas respecto de sus territorios ancestrales, sobre la base de que el respeto de los derechos colectivos de propiedad y posesión de los pueblos indígenas a las tierras y territorios ancestrales constituye una obligación de los Estados miembros de la OEA ${ }^{28}$.

25 Comisión Interamericana de Derechos Humanos. Informe sobre la Situación de los Derechos Humanos en Brasil, Capítulo 6-1, OEA/SerieL/V/II.97 Doc. 29 rev.1, 29 de septiembre de 1997.

26 Tercer Informe sobre Paraguay, párrafo 38.

27 Tercer Informe sobre Paraguay, Cap. IX 9 , 50(8).

28 Ver, por ejemplo, Caso Yanomami; Informe № 75/02, Caso 11.140, Mary y Carrie Cary Dann (Estados Unidos), Informe Anual de la CIDH (2002) [en adelante Caso Dann]; Medidas cautelares, De Vereniging van Saramakaanse (Surinam) (8 de agosto de 2002). 
La Corte Interamericana también ha dado una interpretación amplia a la noción de "propiedad", ampliando su definición para abarcar las tierras de propiedad comunal e incluso a aquellas ocupadas y utilizadas por los pueblos indígenas que ellos no consideran de su "propiedad". El caso emblemático es el de la Comunidad Awas Tingni Mayagna (Sumo) Comunidad Indígena vs. Nicaragua ${ }^{29}$. El caso se originó como una demanda contra la tala de madera en tierras indígenas realizada por Sol del Caribe, S.A. (SOLCARSA), patrocinada por el gobierno. Éste otorgó una concesión maderera a SOLCARSA sin consultar a la Comunidad Awas Tingni, aunque el gobierno había quedado en consultarlos luego de que la comunidad protestara por una anterior concesión maderera otorgada por el gobierno. La denuncia de los Awas Tingni ante la Comisión Interamericana señalaba que el gobierno violó sus derechos a la integridad cultural, la religión, la igualdad de protección y la participación en el gobierno.

En el año 1998, la Comisión Interamericana de Derechos Humanos resolvió el caso a favor de la Comunidad Awas Tingni y los sometió a la Corte Interamericana de Derechos Humanos. El 31 de agosto de 2001, por siete votos contra uno, el tribunal declaró que el Estado había violado los derechos a la protección judicial del artículo 25 y de propiedad del artículo 21, ambos de la Convención Americana. El aspecto más significativo del caso fue la decisión de la Corte de otorgar reparaciones, ya que declaró en forma unánime que el Estado debía adoptar leyes nacionales, reglamentos administrativos y otros medios necesarios para contar con una mensura eficaz, demarcación y mecanismos de título para las propiedades de las comunidades indígenas, de conformidad con el derecho consuetudinario y los valores, usos y costumbres indígenas. Mientras estuviera pendiente la demarcación de las tierras indígenas, el Estado debía abstenerse de realizar o permitir actos de sus agentes o de terceros que pudieran afectar la existencia, valor, uso o disfrute de las tierras de la Comunidad Awas Tingni. Por una votación de 7 a 1, la Corte determinó, asimismo, que el Estado debía invertir US\$ 50.000 en obras públicas y servicios en beneficio colectivo para la Comunidad Awas Tingni como una forma de reparación por daños inmateriales, además de pago de los honorarios y de las costas judiciales.

En el caso de los Mayas de Toledo vs. Belice, la Comisión siguió y expandió lo contenido en el fallo de la Corte en el caso de la Comunidad Awas Tingni y sostuvo que Belice era responsable de la violación de los derechos a la igualdad, propiedad y protección judicial de la Declaración Americana, por haber otorgado concesiones madereras y petroleras, sin proteger las tierras indígenas, sin reconocer y garantizar los derechos territoriales del pueblo Maya sobre dichas tierras ni proveer al pueblo Maya protección judicial de sus derechos debido a las demoras en los trámites judiciales iniciados por el Estado. Asimismo, la Comisión acogió la afirmación de los peticionarios en el sentido de que las contravenciones del Estado habían afectado negativamente el medio ambiente natural del que depende el pueblo Maya para su subsistencia, a pesar de la aseveración del Estado de que los peticionarios no habían proporcionado pruebas suficientes de los impactos ambientales adversos.

La Comisión recomendó que el Estado otorgara al pueblo Maya una reparación efectiva, mediante el reconocimiento de su derecho a la propiedad comunal de las tierras que han ocupado y usado tradicionalmente, sin que se perjudicara otras comunidades indígenas y, además, que realizara la delimitación, demarcación y entrega de los títulos del territorio en el que existe dicho derecho de propiedad comunal, de acuerdo con las prácticas consuetudinarias de uso de la tierra del pueblo Maya. La Comisión recomendó, asimismo, que mientras no se determinara el título de propiedad, el Estado debía abstenerse de realizar cualquier acto que pudiera conducir a los agentes del propio

29 Corte IDH. Caso de la Comunidad Mayagna (Sumo) Awas Tingni Vs. Nicaragua. Excepciones Preliminares. Sentencia de 1 de febrero de 2000. Serie C No. 66 [en adelante Caso Awas Tingni]. 
Estado o a terceros actuando bajo su aquiescencia afectaran la existencia, valor, uso y disfrute de la propiedad ubicada en la zona geográfica ocupada y utilizada por el pueblo Maya.

Uno de los progresos que la Comisión constató en el desarrollo de los derechos de los pueblos indígenas fue el reconocimiento de los derechos de propiedad colectiva ${ }^{30}$. Por su parte, los órganos del sistema interamericano de derechos humanos han reconocido que los pueblos indígenas mantienen una relación particular con las tierras y los recursos que han utilizado y ocupado tradicionalmente, los que consideran de propiedad y disfrute de la comunidad como un todo y como un componente integral de su supervivencia física y cultural y la efectiva materialización de sus derechos humanos en términos más generales ${ }^{31}$. La Comisión determinó que la aplicación de la Declaración Americana a la situación de los pueblos indígenas requiere:

La adopción de medidas especiales para garantizar el reconocimiento del interés particular y colectivo que los pueblos indígenas tienen en la ocupación y el uso de sus tierras y recursos tradicionales y su derecho a no ser privados de este interés excepto con un previo consentimiento plenamente informado, en condiciones de equidad y previa justa compensación ${ }^{32}$.

En consecuencia, el derecho de propiedad en virtud de la Declaración Americana debe ser interpretado y aplicado en el contexto de las comunidades indígenas con debida consideración de los principios relativos a la protección de las formas tradicionales de propiedad y la supervivencia cultural y los derechos a la tierra, territorios y recursos. Se ha afirmado que los anteriores derechos incluyen el derecho de los pueblos indígenas al reconocimiento legal de sus formas y modalidades variadas y específicas de control de la propiedad, uso y goce de territorios, y el reconocimiento de sus derechos de propiedad y posesión respecto de las tierras, territorios y recursos que han ocupado históricamente ${ }^{33}$.

En otro caso acerca de derechos indígenas sobre la propiedad, la Corte determinó en forma unánime que Paraguay había incurrido en una violación de los derechos a la vida, la propiedad, y la protección judicial en el caso de la Comunidad Indígena Sawhoyamaxa ${ }^{34}$. Los demandantes aseveraron que el hecho de no haber garantizado los derechos ancestrales de la comunidad era responsabilidad del Estado, con lo cual se habían vuelto vulnerables a la privación de alimentos, salud y saneamiento. La Corte instó al Estado a realizar la demarcación de las tierras indígenas y a proporcionar un fondo de desarrollo, entre otras reparaciones.

Por último, la Corte amplió considerablemente las garantías de propiedad otorgadas a los pueblos indígenas en su sentencia del año 2007 en el Caso del Pueblo Saramaka vs. Surinam ${ }^{35}$. Al igual que en los casos anteriores, éste se refiere a demandas relacionadas con la propiedad de la tierra y los recursos cuyo origen radica en concesiones otorgadas por el Estado para la exploración y extracción de recursos naturales, no obstante lo cual surgió una importante controversia acerca de si se podía considerar a los Saramaka como comunidad tribal con derecho a las mismas medidas especiales que se otorgan a los pueblos indígenas. Los Saramaka no son un pueblo indígena sino

30 Ver Caso Dann, párrafo 128.

31 Ver, por ejemplo, Caso Awas Tingni, párrafo 149. Informe sobre Ecuador, p. 115.

32 Caso Dann, párr. 131.

33 Ver Caso Dann, párrs. 129-131; Caso Awas Tingni, párr. 151.

34 Comisión Interamericana de Derechos Humanos. Comunidad Indígena Sawhoyamaxa del Pueblo Enxet Vs. Paraguay, Caso 0322/2001, Informe No. 12/03, OEA/SerieL/V/II.118 Doc. 70 rev. 2 at 378 (2003) [en adelante Caso Sawhoyamaxa].

35 Corte IDH. Caso del Pueblo Saramaka Vs. Surinam. Excepciones Preliminares, Fondo, Reparaciones y Costas. Sentencia de 28 de noviembre de 2007. Serie C No. 172 [en adelante Caso Saramaka]. 
descendientes de esclavos africanos traídos a Surinam en el siglo XVII. Sus ancestros escaparon al interior del país, lugar donde establecieron comunidades autónomas.

La Corte determinó que, al igual que otros pueblos tribales, los Saramaka mantienen "una fuerte relación espiritual" ${ }^{\prime 36}$ con el territorio ancestral que constituye una fuente de vida e identidad cultural para el pueblo. La Corte declaró que los miembros del pueblo Saramaka deben ser considerados una comunidad tribal a la que se aplica la jurisprudencia relacionada con la tierra de propiedad indígena y los derechos sobre los recursos, lo que requiere de medidas especiales conforme al derecho internacional de los derechos humanos para proteger su existencia física y cultural. De este modo, la Corte tuvo que determinar cuáles recursos naturales que se encontraban en el territorio tradicional de los Saramaka eran esenciales para la supervivencia de su modo de vida y, en consecuencia, estaban protegidos por las disposiciones del artículo 21 de la Convención.

La Corte concluyó que los recursos relacionados con actividades agrícolas, de caza y de pesca gozan de protección por tratarse de actividades de subsistencia, pero también consideró el impacto de otras actividades sobre los recursos de subsistencia. La Corte trató de lograr un equilibrio. Señaló que el agua limpia es fundamental para la pesca como actividad de subsistencia y que es probable que la calidad del agua se vea afectada por la extracción de recursos que el pueblo Saramaka no utiliza tradicionalmente o no son esenciales para su subsistencia. En efecto, todas las actividades extractivas probablemente tendrán un impacto sobre el uso y disfrute de otros recursos necesarios para dicho pueblo. Sin embargo, la Corte dictaminó que la protección del derecho de propiedad no es absoluta y no se puede interpretar como una disposición que impide el otorgamiento de toda concesión de exploración y extracción en territorio Saramaka. El artículo 21 de la Convención establece la limitación de los derechos de propiedad bajo determinadas circunstancias, pero incluso en los casos en que el Estado cumple con las condiciones establecidas en dicho artículo, la Corte evaluará y dará una importancia crucial a la cuestión de que si esta restricción "implica una denegación de las tradiciones y costumbres de un modo que ponga en peligro la propia subsistencia del grupo y de sus integrantes" ${ }^{37}$.

La Corte estableció tres garantías fundamentales: (1) el Estado debe garantizar la efectiva participación de los miembros del pueblo Saramaka, de conformidad con sus costumbres y tradiciones en relación con todo plan de desarrollo, inversión, exploración o extracción que se lleve a cabo dentro de territorio Saramaka; (2) el Estado debe garantizar que los miembros del pueblo Saramaka se beneficien razonablemente de cualquier plan que se lleve a cabo en su territorio; y (3) el Estado debe garantizar que no se otorgará ninguna concesión dentro del territorio Saramaka a menos y hasta que entidades independientes y técnicamente capaces, bajo la supervisión del Estado, realicen un estudio previo de impacto social y ambiental. Si bien la Corte no las cita directamente, resulta notable la similitud de estos requisitos con las Directrices de Bonn sobre Acceso y Participación Justa y Equitativa en los Beneficios, adoptadas de conformidad con el Convenio sobre Diversidad Biológica. La Corte considera la participación en los beneficios como inherente al derecho de indemnización que reconoce el artículo 21, inciso (2) de la Convención ${ }^{38}$. Dicho derecho de indemnización se extiende a toda privación del uso regular y el disfrute de la propiedad.

El primer deber exige que el Estado recopile y difunda información e implica, además, la realización de consultas de buena fe mediante procedimientos culturalmente adecuados con el fin

36 Caso Saramaka. Párr. 82.

37 Ídem. Párr. 128.

38 El artículo 21(2) establece que "Ninguna persona puede ser privada de sus bienes, excepto mediante el pago de indemnización justa, por razones de utilidad pública o de interés social y en los casos y según las formas establecidas por la ley". 
de llegar a un acuerdo. Al aplicar sus criterios, la Corte determinó que las concesiones otorgadas por el Estado no cumplían con las garantías necesarias, violando así el derecho de propiedad del pueblo Saramaka. La Corte ordenó la demarcación de la tierra de los Saramaka dentro de un plazo establecido y exigió abstención en cuanto a utilizar el territorio hasta que se hubiera realizado la demarcación (a menos que se contara con el consentimiento previo de dicho pueblo); revisión de todas las concesiones ya otorgadas; evaluaciones de impacto ambiental (EIA) que se deberán realizar previo al otorgamiento de nuevas concesiones; y adopción de las medidas necesarias para garantizar la celebración de consultas con el pueblo Saramaka además de una efectiva reparación. La Corte otorgó una indemnización correspondiente a los recursos ya retirados como también una compensación por el monto de US\$ 600.000 correspondiente al daño ambiental y la destrucción de recursos ya producida, suma que debía depositarse en un fondo de desarrollo comunitario creado y establecido por Surinam en beneficio del pueblo Saramaka.

\section{iv. Derechos procesales: información, participación y acceso a la justicia}

La Comisión y la Corte han hecho hincapié en el respeto de los derechos procesales en la mayoría de los casos relacionados con daño ambiental. En el Informe de Ecuador, la Comisión estimó que "la protección del derecho a la vida y a la integridad física deberá concretarse con medidas encaminadas a respaldar y acrecentar la capacidad de las personas para salvaguardar y reivindicar esos derechos" ${ }^{\prime 39}$. En este sentido, los esfuerzos de protección ante condiciones ambientales que constituyen una amenaza para la salud humana "es imperativo que la población tenga acceso a la información, participe en los procesos pertinentes de toma de decisiones y cuente con recursos judiciales" 40 .

En el Informe sobre Ecuador, la Comisión señaló que el acceso a la información es un prerrequisito para la participación pública en la toma de decisiones y para que los individuos puedan supervisar y responder a las acciones de los sectores público y privado. La Comisión hace referencia al artículo 13 de la Convención que otorga el derecho a las personas de buscar, recibir y difundir informaciones e ideas de toda índole. La Comisión recomendó al gobierno tomar medidas que garanticen que dicha información (tal como exige la ley) sea fácilmente accesible para las personas que podrían verse afectadas y recomendó, además, que el Estado adopte medidas para mejorar los sistemas de difusión de la información sobre los temas que les conciernan, la transparencia y las posibilidades de participación pública en los procesos que afecten a los habitantes de los sectores en desarrollo.

La Comisión y la Corte también abordaron el tema del derecho a la información sobre cuestiones ambientales en el caso Claude Reyes et al. Vs. Chile ${ }^{41}$. Los demandantes -organismos no gubernamentales y personas que incluían algunos legisladores chilenos- afirmaban que el Estado de Chile había violado el derecho a la libertad de expresión y el libre acceso a información en poder del Estado (en virtud del artículo 13 de la Convención Americana) ya que el Comité de Inversiones Extranjeras de Chile no divulgó información sobre un proyecto de deforestación que los peticionarios deseaban evaluar. Asimismo, la negativa de los tribunales chilenos de admitir el caso presentado posteriormente contra el Estado de Chile supuestamente constituía una violación del derecho a la protección judicial (artículo 13 de la Convención Americana). El Estado adujo que la información solicitada debía ser considerada confidencial porque "la debida reserva en este

39 Informe sobre Ecuador. Párr. 93.

40 Informe sobre Ecuador. Párrs. 92-93.

41 Corte IDH. Caso Claude Reyes y otros Vs. Chile. Fondo, Reparaciones y Costas. Sentencia de 19 de septiembre de 2006. Serie C No. 151. 
tipo de empresas constituye una de las piezas angulares en materia de garantías constitucionales económicas y de la política chilena de inversión extranjera" ${ }^{42}$. El Estado aseveró, además, que la divulgación de dicha información constituiría una discriminación arbitraria contra los inversionistas. La Comisión declaró admisible el caso y, finalmente, lo presentó ante la Corte.

En su sentencia del año 2006, en que determinó que había violación al derecho de información y el derecho a los recursos judiciales, la Corte citó una serie de documentos, incluyendo no sólo Declaraciones de la OEA sobre gobernanza de la democracia y su propia jurisprudencia, sino también el Principio № 10 de la Declaración de Río sobre el Medio Ambiente y el Desarrollo, resoluciones del Consejo de Europa y de la Convención Aarhus sobre información, participación pública y acceso a la justicia. La Corte ordenó al gobierno diseñar los medios para garantizar el acceso a la información y proporcionar la información solicitada por los demandantes.

Una vez entregada la información, la participación pública en el proceso de toma de decisiones permite que las personas cuyos intereses están en juego puedan manifestar su opinión respecto de los proyectos y actividades que les afecten. La participación pública tiene relación con el artículo 23 de la Convención Americana, que establece que todo ciudadano tendrá derecho "de participar en la dirección de los asuntos públicos, directamente o por medio de representantes libremente elegidos" y tendrá derecho, además, tanto de recibir como de divulgar información (artículo 13). En el Informe de Ecuador, la Comisión recomendó al Estado implementar medidas para garantizar que todas las personas tengan derecho a participar, individual y colectivamente, en la formulación de las decisiones que afectan directamente a su entorno.

En el caso de los Mayas de Toledo, la Comisión señaló que uno de los elementos fundamentales para la protección de los derechos de propiedad de los indígenas es el requisito que establece que los Estados deben realizar consultas efectivas y previamente informadas con las comunidades indígenas respecto de actos y decisiones que puedan afectar sus territorios tradicionales. Ello exige, como mínimo, que todos los miembros de la comunidad sean informados en forma precisa y plena sobre la naturaleza y las consecuencias del proceso y cuenten con una oportunidad efectiva de participar individual o colectivamente ${ }^{43}$. En el caso de los Saramaka, la Corte fue más allá al señalar que los proyectos de gran escala sobre desarrollo o inversiones que pudieran tener un impacto importante en los territorios indígenas y tribales, requieren no sólo consulta, sino también consentimiento previo, libre e informado obtenido conforme con las costumbres y tradiciones ${ }^{44}$ de los pueblos.

Por último, el derecho al acceso a recursos judiciales es considerado la garantía fundamental de los derechos en el plano nacional. Al respecto, el artículo 25 de la Convención Americana establece que "[t]oda persona tiene derecho a un recurso sencillo y rápido o a cualquier otro recurso efectivo ante los jueces o tribunales competentes, que la ampare contra actos que violen sus derechos fundamentales reconocidos por la Constitución, la ley o la presente Convención...". Esto significa que las personas deben tener acceso a recursos judiciales para reivindicar el derecho a la vida, a la integridad física y a vivir en un ambiente seguro, especialmente si dichos derechos están expresamente protegidos por la constitución de un Estado ${ }^{45}$. Las comunidades indígenas y

\footnotetext{
42 Ídem. Párr. 39.

43 Caso de los Mayas de Toledo. Párr. 142.

44 Caso Saramaka. Párr. 134.

45 Informe sobre Ecuador.
} 
locales deben tener acceso a la justicia para garantizar una efectiva protección judicial en cuanto a pretensiones respecto de sus tierras ancestrales ${ }^{46}$.

En la decisión sobre admisibilidad en el caso de la Comunidad de San Mateo de Huanchora y sus integrantes vs. Perú ${ }^{7}$, la Comisión se centró en la naturaleza de los recursos que debe proporcionar el Estado cuando se produce una contaminación grave. Asimismo, señaló las circunstancias bajo las cuales la Comisión emitirá medidas cautelares para hacer frente a las emergencias ambientales. Una coalición de comunidades afectadas por la minería denunció que Perú violó los derechos fundamentales -tanto individuales como colectivos- de sus miembros debido a los efectos de la contaminación producida por un depósito de lodos con desechos tóxicos de propiedad de la empresa minera Lizandro Proaño S.A. Los demandantes alegaron que el Estado era responsable de la violación de una serie de derechos garantizados tanto por la Convención como por la legislación peruana. Según los peticionarios, la mayoría de los habitantes de la comunidad de San Mateo de Huanchora se identifican como indígenas y tienen fuertes lazos espirituales con sus tierras ancestrales, de tal manera que la contaminación afecta no sólo sus valores materiales y su salud, sino también los valores espirituales asociados con la tierra y el medio ambiente.

Los peticionarios solicitaron medidas cautelares, aduciendo que la gravedad de la contaminación ambiental había desencadenado una crisis de salud pública y que cada día aumentaba el riesgo ocasionado por exposición a los metales contenidos en los lodos. El 17 de agosto de 2004, la Comisión adoptó medidas cautelares y solicitó al gobierno de Perú que, dentro de un plazo de 15 días, informara si estaba tomando las medidas específicas (señaladas por la Comisión) para enfrentar la crisis de salud pública.

Perú insistió en que los recursos internos no se habían agotado, por lo que la petición era inadmisible y señaló, además, que el gobierno había iniciado un procedimiento penal en contra del director de la empresa minera, que el sistema nacional contaba con disposiciones adecuadas para enfrentar el problema y que se había iniciado un procedimiento administrativo para detener las actividades de la empresa minera y eliminar el vertedero de lodos tóxicos. Sin embargo, aunque el gobierno afirmó que había dado órdenes de cerrar definitivamente el vertedero de residuos tóxicos de Mayoc y estaba desarrollando un plan para eliminar los contaminantes, estos aún no habían sido retirados.

La Comisión reiteró que los recursos debían ser adecuados y efectivos y sólo se deben agotar aquellos recursos que son apropiados para reparar las violaciones presuntamente cometidas. "Adecuado" significa que el funcionamiento de dichos recursos, en el marco de la legislación nacional, debe ser tal que sirva para remediar la situación legal que se infringió. Un recurso es efectivo cuando es capaz de lograr el resultado para el cual fue creado ${ }^{48}$. Según este criterio, la Comisión estableció que los recursos utilizados por los peticionarios no eran efectivos, pues no los proveían de la protección jurídica que buscaban. Las decisiones administrativas adoptadas no se cumplieron y habían transcurrido más de 3 años sin que hubiera un veredicto en la causa criminal y, mientras tanto, el lodo de los desechos tóxicos seguía perjudicando la salud de los integrantes de la comunidad, con efectos que se hacían cada vez más graves. En consecuencia, la Comisión estimó que las disposiciones de la Convención Americana en cuanto al agotamiento de los recursos internos no eran aplicables, por lo que era admisible la demanda presentada.

\footnotetext{
46 Ver: Caso Sawhoyamaxa; Caso Awas Tingni; Corte IDH. Caso Comunidad Indígena Yakye Axa Vs. Paraguay. Fondo Reparaciones y Costas. Sentencia 17 de junio de 2005. Serie C No. 125, párr. 387.

47 Admisibilidad, Informe No 69/04, Petición 504/03 (Oct. 15, 2004).

48 Caso Velásquez Rodríguez, párrs. 63-64; Caso Godínez Cruz, párrs. 66-67; Corte IDH. Caso Fairén Garbi y Solís Corrales Vs. Honduras. Fondo. Sentencia de 15 de marzo de 1989. Serie C No. 6, párrs. 87-88.
} 
A fines del año 2007, la Comisión emitió un informe sobre el acceso a la justicia en el cual recopiló las normas y estándares hemisféricos sobre este tema ${ }^{49}$. Los estándares establecen claramente la obligación positiva de los Estados de eliminar cualquier obstáculo normativo, social o económico que impida o dificulte la posibilidad de tener acceso a la justicia, así como su obligación de garantizar un juicio justo dentro de un plazo razonable y una decisión razonada basada en el fondo del asunto. Los recursos judiciales deben ser simples, inmediatos, informales, accesibles y elaborados por organismos independientes.

\section{v. Límites de la jurisdicción}

La Comisión y la Corte han estado menos dispuestas a examinar casos en que los temas ambientales se extienden más allá del bienestar de los seres humanos. En el año 2004, la Comisión declaró inadmisible la petición presentada por un ciudadano panameño respecto del Parque Natural Metropolitano en Panamá, dado que la petición no individualizaba víctimas concretas y era excesivamente amplia ${ }^{50}$. El peticionario alegaba que el gobierno había violado el derecho a la propiedad de todos los ciudadanos panameños al permitir la construcción de un proyecto vial que atravesaba una reserva natural protegida. Sostuvo que el estatus de reserva natural convertía al lugar en propiedad de todos los ciudadanos y no del Estado. Después de ocho años, la Comisión determinó que, en vista de que no se habían identificado víctimas específicas, la demanda era inadmisible y calificó el caso como una actio popularis junto con reconocer el problema que esta situación generaba para el peticionario: "[La Comisión aprecia que] por la naturaleza de los hechos descritos en la petición tampoco es posible identificar un grupo definido de víctimas, pues el peticionario se ha referido a todos los ciudadanos de Panamá como propietarios del Parque Natural Metropolitano" ${ }^{51}$. Lamentablemente, el análisis de la Comisión sugiere que cuanto más amplias y generalizadas sean las violaciones -lo cual puede ocurrir en muchos contextos en que el daño ambiental constituye la base de la denuncia- es menor la probabilidad que la denuncia sea considerada admisible.

\section{Conclusiones}

El enfoque basado en los derechos analizados precedentemente tiene ventajas significativas respecto de otros mecanismos legales que tienen por objeto lograr la protección del medio ambiente. En primer lugar, los derechos humanos son un derecho superlativo ante la sociedad, al colocar la preocupación por el medio ambiente por encima de una mera opción de políticas que se puede modificar o descartar a voluntad. Los derechos constituyen atributos inherentes que deben ser respetados en toda sociedad bien organizada. El peso moral de este concepto ejerce una fuerza importante en cuanto a su cumplimiento. En segundo lugar, cuando el derecho sobre el medio ambiente ha sido consagrado como garantía constitucional, por lo general, se encontrará en la cima de la jerarquía jurídica nacional y se impondrá por encima de cualquier norma de inferior valor que contradiga, lo cual le otorga precedencia respecto de otras normas legales que no se basan en la constitución. En tercer lugar, en el plano internacional, la capacidad de hacer cumplir el derecho de los derechos humanos se encuentra más desarrollada que los procedimientos del derecho internacional sobre el medio ambiente. La existencia de mecanismos individuales de

49 Comisión Interamericana de Derechos Humanos. El acceso a la justicia como garantía de los derechos económicos, sociales y culturales. Estudio de los estándares fijados por el Sistema Interamericano de Derechos Humanos. OEA/ Ser.L/V/II.129. Doc. 4.7 septiembre 2007. Original: Español.

50 Petición 11.533 (Panamá), Informe No. 88/03, Informe Anual 2003.

51 Ídem. Párr. 34. 
denuncia ha dado origen a una vasta jurisprudencia a partir de la cual se han pormenorizado las obligaciones específicas de los Estados acerca de la protección y preservación del medio ambiente.

Las decisiones y sentencias dictadas por la Comisión y la Corte Interamericanas reflejan tres enfoques importantes: han reconocido que el deterioro del medio ambiente puede implicar violaciones de los derechos a la vida, la salud, la propiedad y la cultura; han subrayado la importancia de derechos tales como el de información, participación pública en la toma de decisiones (incluyendo el previo consentimiento informado de parte de los propietarios que pudieran verse afectados en forma negativa por proyectos de desarrollo), y el derecho de acceso a la justicia y recursos efectivos para garantizar la protección de otros derechos; por último, ambos organismos han insistido en que será necesario implementar y hacer cumplir las garantías constitucionales respecto del derecho a un medio ambiente seguro, sano y sin deterioro ecológico.

Evidentemente, los Estados ya no gozan de plena discreción para determinar el nivel de protección del medio ambiente, ni para decidir libremente respecto de la cantidad y calidad de los proyectos de desarrollo que podrían aprobar. Las garantías de los derechos humanos sirven para imponer un nivel mínimo de calidad ambiental que se debe garantizar frente a actividades estatales y no estatales. Los Estados también deben proporcionar información sobre las condiciones ambientales y asegurar que todas las personas y grupos que estén potencialmente afectados por un posible proyecto o actividad tengan acceso a las instancias necesarias para participar en el proceso de toma de decisiones. Una vez aprobado un proyecto o actividad, el Estado debe aplicar plenamente las leyes y reglamentos correspondientes que hayan adoptado. Por último, el Estado debe crear mecanismos de cumplimiento y reparación.

Las decisiones de las instituciones interamericanas han aglutinado los valores fundamentales de la comunidad internacional, otorgando reconocimiento a la importancia del desarrollo económico en el hemisferio junto con asegurar que los derechos humanos y la protección del medio ambiente serán respetados. El término "desarrollo sostenible" que se adoptó en la Declaración de Río sobre Medio Ambiente y Desarrollo refleja adecuadamente esta tríada de intereses, que deben ser tomados en cuenta por los diferentes gobiernos y organizaciones internacionales. No es posible lograr ni uno solo de estos tres objetivos -la protección del medio ambiente, el desarrollo económico y el respeto de los derechos humanos- sin tomar en consideración los otros dos. 